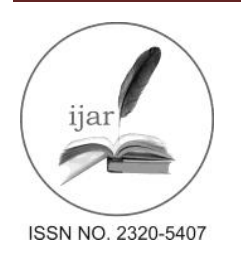

Journal homepage: http://www.journalijar.com

Journal DOI: 10.21474/IJAR01

INTERNATIONAL JOURNAL

OF ADVANCED RESEARCH

RESEARCH ARTICLE

\title{
SELF EFFICACY AND LOCUS OF CONTROL AS MEDIATORS OF STRESS IN ADOLESCENTS: USHERING IN AN AGE OF SELF-EVOLUTION.
}

\author{
Dr. Giselle D'souza. \\ Associate Professor, St. Teresa's Institute of Education, Mumbai, India.
}

\section{Manuscript Info}

\section{Manuscript History:}

Received: 10 March 2016

Final Accepted: 19 April 2016

Published Online: May 2016

Key words:

Stress, Self-efficacy, Locus of

Control

*Corresponding Author

Dr. Giselle D'souza.

\begin{abstract}
Stress has been linked to increased illness in several biologically based studies (Roddenberry, A. 2007). In contrast, only a limited number of studies have assessed self-efficacy and locus of control serving as potentially important variables related to stress. As Gautam Buddha rightly said, "We are what we think. All that we are arises with our thoughts." Since the aim of education must transcend the development of academic competence, schools need to become aware of their added responsibility of preparing self-assured and fully-functioning individuals. Students need to emerge capable of pursuing their hopes and ambitions instead of being vulnerable to the devastating effects of stress.
\end{abstract}

The present research endeavor attempted to identify the relationship of two self-constructs namely, self-efficacy and locus of control with stress encountered by adolescents using the semi-partial correlation method. The sample comprised of 1092 students aged between 13-14 years. Results indicated a significant correlation among the selected variables indicating that high self-efficacy and locus of control both help in reducing stress levels. The study also attempted to examine the relationship between selfefficacy and locus of control using Karl Pearson's coefficient of correlation. Findings of the study revealed a strong positive correlation between these two self-constructs. This indicates that helping students to come to terms with the invaluable worth of their self-efficacy would help them be in total control of their own lives. This paper also proposes constructive strategies to enhance the self-worth of students so as to usher in an age of self-evolution and alleviate stress.

Copy Right, IJAR, 2016.. All rights reserved.

\section{Introduction:-}

"Stress" is the watchword of the present millennium. It has come to pervade every arena of human life; education being no exception, rendering students as helpless victims of this killer disease. The educational landscape today stands disfigured by a spate of innumerable student suicides resulting from adolescents resorting to take the extreme step of ending their lives simply because they are unable to cope with the anxieties and pressures they encounter during their growing up years. Student stress has been a growing cause of concern since the recent years as the threats of competition and achievement loom large and low over the student fraternity. Several studies have investigated the different types of stress encountered by students and have revealed that achievement pressure, examinations and social events rank highest on the list of stressors (Philips, 1978). Adolescence is a stressful period as individuals are not longer viewed as children but, nonetheless, are considered to be too immature to be treated as adults. Irvine (2000) identifies a range of stressors in children from parental divorce and separation, to academic and social failure. Throughout the adolescent years, stressful experiences are also considered to be increasing in intensity, as prominent stressors involving family dysfunction, peer demands and academic concerns are faced by adolescents (Frydenberg, 1991). Major public examinations like the Secondary School Certificate (SSC) and Higher 
Secondary Certificate (HSC) are classed as "high-stakes assessments", where the results of exams could have major consequences for the student. In India, student performance in standard 10 determines entry into college, which means marks become determinants of career paths. Students can feel academic pressure when the perceived level of expectation or consequence exceeds what they believe they can achieve. This can lead to stress and altered learning behaviours. Even worse, it can make the smartest students do poorly in their exams. A survey of Year 12 students from a range of schools in Sydney revealed similar findings. Of the 722 students surveyed, $44 \%$ identified themselves as the greatest source of pressure, with $35 \%$ attributing family and $21 \%$ the school or teachers as the other main sources. More gifted students (47\%) than their average-ability peers $(24 \%)$ identified their own internal pressure as the strongest source of pressure (North et al, 2015). A study assessing the sources and levels of stress (i.e. academic and life stress) in relation to locus of control and self-esteem in college students revealed that examinations and examination results were the most important causes of stress for these students (Abouserie, 1994). In addition, this study suggested that $88 \%$ of college students who were stressed by examinations fell in the moderately to severely stressed categories, with female students reporting more stress than male students.

Personality correlates have been gaining importance in the context of stress management over the last few decades. Individuals' feelings that they are in control of their own internal psychological environment (i.e., cognition, beliefs, emotions, and thoughts) and its outward behavioral expression have been associated with feelings of psychological well-being (Shapiro et al., 1996). Given this relationship, individuals' perceptions of the control that they have over stressful situations may serve as an important predictor of their responses to stress. Research has suggested that psychologically healthy individuals have a greater sense of control than do those suffering from psychological distress or impairment. Further, these healthy individuals have been found to overestimate the amount of control that they have in a situation, to be more optimistic about their ability to achieve control, to overestimate their invulnerability, and to underestimate risk in certain situations (Lewinshon, Mischel, Chaplin, and Barton, 1980; Seligman, 1991; Taylor and Brown, 1988). They also tend to make explanatory attributions to protect their sense of control when behavioral control efforts are not successful. They tend to attribute unsuccessful outcomes to external rather than internal factors. Findings of a study by Horner (1996) revealed that external locus of control was associated with higher levels of actual stressors, higher levels of neuroticism, the use of more emotion-directed coping behaviors, and higher levels of perceived stress. Bandura (1977) proposed that individuals' expectations of personal efficacy determine whether coping behavior will be initiated, the amount of effort that they will expend, and how long they will sustain the effort in the face of obstacles or aversive experiences. The relationship between individuals' perceived self-efficacy and their beliefs regarding their control over stressors on components of the immunological system has been examined (Wiedenfeld et al., 1990). Results revealed that perceived self-efficacy moderated immunological system responses. When individuals felt that they were gaining self-efficacy over a stressor, the effects of the stressor on the immune system decreased. Thus, individuals' feelings that they could exercise self-efficacy and control over a stressor reduced the negative effects of stress on the immune system. This study supported the protective function of self-efficacy in reducing the body's response to stress, in that self-efficacy was found to moderate the relationship between stress and immune system response. In addition, locus of control and self-efficacy are two constructs that have been studied together recently with regard to the relationship between distress and illness (Shelley and Pakenham, 2004). However, this relationship needs to be examined more closely. The present study was an attempt to bring to light the connect between these two self-constructs so that the former could be enhanced using constructive strategies in a bid to help students be in control of their own lives thus alleviating the stress they encounter. 'Stress' in this research is defined as a reaction to any event in which environmental demands, internal demands, or both, tax or exceed the adaptive resources of a student. 'Self-Efficacy' (SE) refers to a student's convictions and confidence about his / her abilities to mobilize the motivation, cognitive resources and courses of action needed to excel in his/her studies and thereby achieve success at the standard 10 examination. 'Locus of Control' (LOC) refers to a student's perception of the factors responsible for their successes or failures and their generalized expectations concerning where control over subsequent events resides.

\section{Subjects and Methods:-}

\section{Subjects:-}

The study was co-relational because it aimed to assess the combined relationship of self-efficacy and locus of control with stress as well as the relationship between SE and LOC alone. A 3.5 percent sample was taken and the sample size was arrived at through the use of power analysis (Creswell, 2002). The school sample consisted of 1092 adolescents selected from 20 secondary schools of Greater Mumbai with English as the medium of instruction and affiliated to the Secondary School Board. 


\section{Methods:-}

The rating scales used to assess stress, self-efficacy and locus of control in the present study were prepared by the researcher. Face and content validity were ascertained by getting the tools validated by subject experts from the fields of Education and Psychology. Item discrimination index was also calculated by carrying out a pre-pilot study. Internal consistency reliability and test-retest reliability were calculated by conducting the pilot study (D'souza, 2012). After collection of data, the responses of the students were quantified by assigning scale values to the items.

\section{Statistical Analysis:-}

The scores were tabulated and then analysed using descriptive and inferential analysis. Descriptive analysis included the magnitude of the variables for the Total Number of Students (TNS). Inferential statistics was carried out using Karl Pearson's coefficient of correlation to determine the relationship between SE and LOC and semi-partial correlation to determine the relationship of SE and LOC with stress. When P value was less than 0.05 , the difference was considered statistically significant and highly significant when P-value was less than 0.01 or 0.001 .

\section{Results:}

Table 1 shows magnitude of the variables of the Total Number of Students in terms of mean percentage. The findings indicate that the magnitude of stress was moderate, while that of Self-efficacy and Locus of Control was substantial.

Table 1: Magnitude of the variables of the study.

\begin{tabular}{|c|c|c|}
\hline Variable & Percent Mean & Magnitude \\
\hline Stress & 47.67 & Moderate \\
\hline Self-Efficacy (SE) & 68.73 & Substantial \\
\hline Locus of Control (LOC) & 77.57 & Substantial \\
\hline
\end{tabular}

Table 2 shows the significance of the coefficient of correlation ' $r$ ' between Self-Efficacy and Locus of Control in the Total Number of Students as calculated by Karl Pearson's Coefficient of Correlation. The correlation co-efficient indicates that the relationship between these two self-constructs is positive and moderate in magnitude. Thus, enhancing either one of them in students would lead to a corresponding increase in the other.

Table 2:- Significance of ' $r$ ' between SE and LOC.

\begin{tabular}{|c|c|c|c|}
\hline $\mathbf{N}$ & $\begin{array}{c}\text { Degrees } \\
\text { of freedom }(\mathbf{d f})\end{array}$ & $\begin{array}{c}\mathbf{r} \\
(\mathbf{S E} \times \text { LOC })\end{array}$ & Level of significance \\
\hline 1092 & 1090 & 0.544 & 0.01 \\
\hline
\end{tabular}

SE: Self-efficacy LOC: Locus of Control $\mathrm{N}=$ Number of students $\mathrm{df}=\mathrm{N}-2$

' $\mathrm{r}$ ' is the coefficient of correlation

$\mathrm{P}$ (level of significance) of 0.01 is considered to be highly significant.

Table 3 shows the first order partial correlation coefficients between stress, self-efficacy and locus of control. The findings reveal that self-efficacy has a greater role to play in reducing stress levels than does locus of control. Further, it implies that higher the self-efficacy and locus of control of students, lower is likely to be the stress perceived by them. The results are highly significant as $\mathrm{P}<.0001$.

Table 3:- First order partial correlation of the selected variables.

\begin{tabular}{|c|c|c|c|c|}
\hline & $\mathbf{r}$ & $\mathbf{r}^{2}$ & $\mathbf{t}$ & $\mathbf{P}$ \\
\hline XY.Z & -0.399 & 0.159 & -14.35 & $<.0001$ \\
\hline XZ.Y & -0.284 & 0.081 & -9.78 & $<.0001$ \\
\hline YZ.X & 0.365 & 0.133 & 12.93 & $<.0001$ \\
\hline
\end{tabular}

' $r$ ' is the first order partial correlation coefficient

$P$ values are non-directional (two-tailed)

X: Stress Y: Self-Efficacy Z: Locus of Control

\section{Discussion:-}

The results of the study indicate that self-efficacy and locus of control are negatively correlated with stress. This is substantiated by research evidence from a study done by Abouserie (1994) with regard to the relationship between stress, locus of control, and self-esteem which revealed that those with external locus of control beliefs were more stressed than those with internal locus of control beliefs. Further, those with high self-efficacy were less stressed 
than were those with low self-efficacy. Gadzella (1994) in an earlier study concluded that those who are external scorers are more likely to experience higher levels of stress. Findings suggest that the relationship between stress and locus of control may be multifaceted. In particular, it may be that different levels of stress are related to the different dimensions of locus of control in unique ways. A more recent study assessed the effects of academic stress in undergraduate students on self-control (Oaten and Cheng, 2005). Results revealed that the anticipation of academic examinations depleted self-control strength and produced subsequent failures in self-control behavior. Studies assessing the relationship between stress and control in students, although limited in number, have supported the link between external locus of control and stress as well as between the negative effects of exam stress and individuals' self control and health behaviors. The potential moderating effect of locus of control on this relationship also was examined (Bollini et al, 2004). Findings revealed that those with a high external locus of control reported more psychological and physical problems and less life satisfaction and efficacy. In addition, these individuals perceived themselves as having less control, being more susceptible to external influences, and more responsive to stress.

Given the links established between stress, locus of control, and negative physical outcomes by earlier studies, further investigation is needed to evaluate mediators of these relationships using a real world stress condition. In this respect, the present study fills in the existing lacunae in stress research, as it focuses on students of standard 10 who are the victims of examination stress caused by irrational fears of facing the threat of high achievement at their first public examination. Moreover, being at the adolescent stage they have to cope with the dual pressure of physical and emotional changes that are characteristic of this stage of development. The findings of this research endeavour ascertain that self-efficacy and locus of control could be considered as powerful mediators of stress in adolescents.

The present study also revealed a moderately positive relationship between the two self-constructs self-efficacy and locus of control. This finding opens up the possibility that a high self-efficacy could help students develop a correspondingly high locus of control. This finding has important implications for the area of stress management in students. Teachers and educators could emphasize developing the self-worth of adolescents by guiding them in attribution training, positive self-talk, self-appreciation, getting rid of perfectionism, getting out of the comparison trap and setting realistic goals. Schools could organize programmes on building resilience and conduct courses in relaxation and yoga as well as sessions on effective coping. Co-operative learning techniques and peer tutoring could also help students to build a healthy self-concept as they realize and appreciate their own strengths in reaching out to another. Teachers could also replace judgmental comments in evaluation of students with encouraging, motivating and constructive criticism. Providing adolescents with exemplary role models to emulate in the context of their times could serve as a big booster in stepping up their feelings of self-worth. Sociometric techniques could provide valuable insights to a classroom teacher to help identify the stars and isolates of a class. Teachers could then entrust students who are sidelined by others with responsibilities so as to give them a chance to demonstrate their leadership skills and potential. In doing so it would help students who have a poor self-image develop a sense of self-confidence and scale greater heights as they get in control of their own lives.

In conclusion, it can be reiterated that helping students to come to terms with the invaluable worth of a high self-efficacy and an internal locus of control would lead them to believe that they are persons of value and worth, hence deserving high self-regard and possessing a healthy measure of built in self-esteem. It would teach them not to hide behind a mask of self-doubt or insecurity but instead, learn to take criticism in their stride, not get overwhelmed by feelings and never over react to stressful situations. It is only when these goals are accomplished that education would find its true meaning in ushering in an age of self-evolution.

\section{Acknowledgement:-}

The researcher is extremely grateful to her research guide Prof. Dr. Shefali Pandya, (Professor. Department of Education, University of Mumbai, India.) for her unstinted support, resourceful inputs and valuable guidance in bringing this study to fruition. 


\section{References:-}

1. Abouserie, R. (1994): Sources and levels of stress in relation to locus of control and self-esteem in university students. Educational Psychology., 14: 323-331.

2. Bandura, A. (1977): Self-efficacy: Toward a unifying theory of behavioral change. Psychological Review., 84: 191-215.

3. Bollini, A. M., Walker, E. F., Hamann, S., and Kestler, L. (2004): The influence of perceived control and locus of control on the cortisol and subjective responses to stress. Biological Psychology., 67: 245-260.

4. Creswell, J.W. (2002): Educational Research: Planning, Conducting and Evaluating Quantitative and Qualitative Research. University of Netvaska: Merill. Prentice Hall.

5. D'souza, G. (2012): Stressed but Not Out: Helping Students discover the Power of Self. New Delhi: APH Publishing Corporation.

6. Frydenberg, E. (1991): Adolescent coping: The different ways in which boys and girls cope. Journal of Adolescence., 14: 119-133.

7. Gadzella, B. (1994): Locus of control differences among stress groups. Perceptual and Motor Skills., 79: 16191624.

8. Horner, K. (1996): Locus of control, neuroticism, and stressors: Combined influences on reported physical illness. Personality and Individual Differences., 21: 195-204.

9. Irvine, J. (2000): Thriving at school. New South Wales: Simon and Schuster. Journal of Psychology., 56: 191-199.

10. Lewinshon, P. M., Mischel, W., Chaplin, W., and Barton, R. (1980): Social competence and depression: The role of illusory self-perceptions. Journal of Abnormal Psychology., 89: 203-212.

11. North, B.et al. (2015): The conversation. http://theconversation.com/study-confirms-hsc-exams-source-ofmajor-stress-to-adolescents-46812 Retrieved on $3^{\text {rd }}$ May 2016.

12. Oaten, M, \& Cheng, K. (2005): Academic examination stress impairs self-control. Journal of Social and Clinical Psychology., 24: 254-279.

13. Philips, B. (1978): School Stress and Anxiety - Theory, Research and Intervention. U.S.A: Library of Congress Cataloging in Publication Data.

14. Roddenberry, A. (2007): Locus of Control and Self-efficacy: Potential Mediators of Stress, Illness, and Utilization of Health Services in College Students. Doctoral Dissertation. University of Central Florida.

15. Seligman, M. E. P. (1991): Learned optimism. New York: Knopf.

16. Shapiro, D. H., Schwartz, C. E., and Astin, J. A. (1996): Controlling ourselves, controlling our world. American Psychologist., 51: 1213-1230.

17. Shelley, M., and Pakenham, K. I. (2004): External health locus of control and general self-efficacy: Moderators of emotional distress among university students. Australian Journal of Psychology., 56: 191-199.

18. Taylor, S. E., and Brown, J. D. (1988): Illusion and well-being: A social psychological perspective on mental health. Psychological Bulletin., 103: 193-210.

19. Wiedenfeld, S. A., Bandura, A., Levine, S., O’Leary, A., Brown, S., and Raska K. (1990): Impact of perceived self-efficacy in coping with stressors on components of the immune system. Journal of Personality and Social Psychology., 59: 1082-1094. 